\title{
Flood design recipes vs. reality: can predictions for ungauged basins be trusted?
}

\author{
A. Efstratiadis ${ }^{1}$, A. D. Koussis ${ }^{2}$, D. Koutsoyiannis ${ }^{1}$, and N. Mamassis ${ }^{1}$ \\ ${ }^{1}$ Department of Water Resources and Environmental Engineering, National Technical University of Athens, Athens, Greece \\ ${ }^{2}$ Institute of Environmental Research and Sustainable Development, National Observatory of Athens, Athens, Greece
}

Correspondence to: A. Efstratiadis (andreas@itia.ntua.gr)

Received: 30 October 2013 - Published in Nat. Hazards Earth Syst. Sci. Discuss.: 11 December 2013

Revised: 25 February 2014 - Accepted: 21 April 2014 - Published: 5 June 2014

\begin{abstract}
Despite the great scientific and technological advances in flood hydrology, everyday engineering practices still follow simplistic approaches that are easy to formally implement in ungauged areas. In general, these "recipes" have been developed many decades ago, based on field data from typically few experimental catchments. However, many of them have been neither updated nor validated across all hydroclimatic and geomorphological conditions. This has an obvious impact on the quality and reliability of hydrological studies, and, consequently, on the safety and cost of the related flood protection works. Preliminary results, based on historical flood data from Cyprus and Greece, indicate that a substantial revision of many aspects of flood engineering procedures is required, including the regionalization formulas as well as the modelling concepts themselves. In order to provide a consistent design framework and to ensure realistic predictions of the flood risk (a key issue of the 2007/60/EU Directive) in ungauged basins, it is necessary to rethink the current engineering practices. In this vein, the collection of reliable hydrological data would be essential for re-evaluating the existing "recipes", taking into account local peculiarities, and for updating the modelling methodologies as needed.
\end{abstract}

\section{Introduction}

Disasters caused by large floods increase worldwide as a result of the changing environment (urbanization, deforestation), despite better infrastructures, better forecasting systems and better urban planning and management. For example, a number of catastrophic floods have occurred in Europe and in the USA in the last two decades, causing extensive damage and loss of human life (Kundzewicz et al., 2013). Such events have alerted society to the severity of the problem, adding urgency to the need for control of flood hazards. Within this context, the European Union has adopted the Directive 2007/60/EC on the assessment and management of flood risks that highlights the social, environmental and economic aspects of the problem. This "Flood Directive" also specifies a series of actions aimed at reducing the risks and consequences due to these natural disasters. Its implementation requires advanced methodologies for the proper estimation of flood risk and the mapping of potential hazards.

However, in the context of everyday flood engineering practice, the majority of routine (low-cost) studies use naïve and outdated formulas or models, applying them as "recipes". Indeed, most of the widely employed semiempirical approaches for estimating flood design "loads" were developed many decades ago, yet have been only occasionally validated, updated and adapted to local conditions. Obviously, this can have an impact on the safety and cost of the designed hydraulic structures, as undersizing exposes them to increased risk of failure while oversizing causes unnecessary expenditure. On the other hand, while common flood engineering practice is well behind advances in hydrological science, little attention is actually paid (including EU research policy) to mitigating this gap (Koutsoyiannis, 2014).

In the sequel we discuss three key issues of flood design "loads" estimation. The first critical issue refers to the misuse of certain common flood models that are usually handled as rules of thumb, providing deterministic results. Taking as example the computationally simplest of these models, the rational method, we show that great experience and 
engineering judgment are essential prerequisites for applying this deceptively simple method. Further, we employ Monte Carlo simulation to reveal the significant uncertainty in the results of the rational method due to inherent uncertainties in the estimation of its input parameters. Then, we comment on the concept and the application of regional formulas for estimating the input parameters of certain popular flood models. Regional formulas have been typically derived through regression analysis of observed data gathered at a limited number of experimental areas. Taking as example the time of concentration, one of the most important parameters in flood modelling, we evaluate the performance of some widely used formulas against a large data set of peak flows from Cyprus. Finally, we draw attention to the potential pitfalls of using the well-known unit hydrograph approach, as exemplified by combining it with the Soil Conservation Service Curve Number (SCS-CN) method, for estimating design hydrographs in rural basins. The key hypothesis of this, and similar methods, is the dominance of overland runoff during a flood event. On the basis of observed flood data from small catchments in Greece and Cyprus, we demonstrate that this hypothesis is rather inconsistent with the response of rural basins, in which the dominant mechanism is interflow.

\section{Handling flood design by means of "recipes": lessons learned from the rational method}

\subsection{The rational method as (deterministic) recipe}

The rational method, introduced about 150 years ago and credited either to Mulvaney (1851) or to Kuichling (1889) (Chow, 1964, Ch. 14, p. 6), is still being used widely around the world today for flood peak estimation in small ungauged basins and for the design of urban storm drainage systems. An important reason for this method's attractiveness to hydrologists and to authorities alike is certainly its simplicity: the model consists of the single equation

$Q_{\mathrm{p}}=C i A$.

This equation purports to estimate the peak discharge $Q_{\mathrm{p}}$ from a drainage basin of area $A-$ the "loss" characteristics of which (infiltration etc.) are (supposedly) encapsulated in the constant dimensionless runoff coefficient $C$ - when the drainage basin receives a gross rainfall of constant intensity $i$ over a time period at least equal to the basin's time of concentration $t_{\mathrm{c}}$.

Application of the rational formula involves the task of selecting an appropriate $C$ value and specifying the rainfall intensity for use with an intensity-duration-frequency curve $i(T, d)$ (henceforth referred to as the ombrian curve, from the Greek word for rain, ombros), $T$ being the return period of a uniformly distributed rainfall of intensity $i$ and duration $d$. Since that duration is equal to the time of concentration, the latter quantity must be estimated as well. The implementation of the rational method is based on the following procedure:

a. fitting a statistical model to a sample of observed rainfall maxima, resolved to temporal scales ranging from few minutes to one day or more, and derivation of the ombrian curve $i(T, d)$;

b. estimating the time of concentration $t_{\mathrm{c}}$ of the basin, by using one of the many regional formulas available from the literature, and setting the rainfall duration $d$ equal to $t_{\mathrm{c}}$;

c. computing a point intensity of rainfall, via the ombrian curve, which is then adjusted for application on the basin area by multiplication with a suitable areal reduction factor;

d. specifying a runoff coefficient from tabulated values that are related to the physiographic characteristics of the basin; and

e. evaluating Eq. (1).

The rational method's elementary concept and the simplicity of Eq. (1) often misleadingly prompt towards a recipe-like application. In reality, however, all steps of the procedure described above involve critical assumptions and estimations for which a number of open research questions exist. These issues are synoptically described below.

\subsubsection{Selecting "rational" statistical models for rainfall description}

Statistical modelling is of key importance in flood engineering. In particular, the construction of ombrian curves is the most common task related to the probabilistic description of extreme rainfall. For many decades, the Gumbel distribution (EV1) was the prevailing model of extreme rainfall; a major reason for this is its computational simplicity: EV1 is one of very few statistical models with analytical expressions of both the distribution function and its parameters.

Many researchers have criticized this distribution, on theoretical and on empirical grounds. In particular, Koutsoyiannis and Baloutsos (2000), Koutsoyiannis (2004a, b) and Papalexiou and Koutsoyiannis (2012), comparing actual and asymptotic extreme value distributions, found that the extreme value type II distribution gives, by far, the most consistent representation of rainfall maxima. By investigating large rainfall samples worldwide, they also proved that the Gumbel distribution may significantly underestimate the largest extreme rainfall amounts, although its performance is satisfactory for return periods less than 50 years.

\subsubsection{The time of concentration enigma}

The time of concentration, $t_{\mathrm{c}}$, is a key characteristic of the river basin and a key issue in flood modelling, but also an ambiguous concept (Huber, 1987). McCuen (2009) reports eight 
different definitions for $t_{\mathrm{c}}$, the most typical of which is the longest travel time of the surface runoff to the basin outlet. In theory, $t_{\mathrm{c}}$ could be inferred from observed rainfall-runoff data sets, provided that the actual losses and the direct runoff were known; in fact, however, some kind of a model must be used to estimate these quantities (see Sect. 4). For ungauged basins, $t_{\mathrm{c}}$ is computed by empirical formulas that are based on the basin response time as function of its lumped geomorphological characteristics (see Table 2 for certain popular formulas). Advanced methods also take advantage of GIS tools to represent the spatial distribution of overland flow velocity over the catchment. All these approaches yield a wide range of $t_{\mathrm{c}}$ values.

Huber (1987) astutely asserted that the proper characteristic time for $t_{\mathrm{c}}$ is the wave travel time from the hydraulically most remote point of a basin to its outlet. Thus defined, the time of concentration is the time that results in maximum flow rate at the basin outlet. However, this travel time is not constant, but inversely proportional to the rainfall. Indeed, Grimaldi et al. (2012c) found that $t_{\mathrm{c}}$ varied by even one order of magnitude across rainfall events of different intensities. The variability of $t_{\mathrm{c}}$ is explained by the dependence of the kinematic wave celerity on the flow rate (nonlinearity, e.g. Koussis, 2009, 2010). It is noted, however, that, for overland flow in natural drainage basins, the practical computation of travel time based on the well-established theory of flood wave motion is fraught with uncertainties.

In summary, despite theoretical proof and empirical evidence that $t_{\mathrm{c}}$ varies significantly with the flow, and thus also with $Q_{\mathrm{p}}$, in the context of the rational method the time of concentration is considered a "basin constant" that determines $Q_{\mathrm{p}}$ ! Solving this enigma of engineering hydrology finding the "basin constant" $t_{\mathrm{c}}$ - naturally demands great experience and engineering judgment.

\subsubsection{From point to areal rainfall estimations}

Although the statistical analysis of rainfall extremes and the construction of ombrian curves refer to a point (i.e. the rainfall station), the critical intensity in the rational equation should refer to the catchment area. Therefore, a transformation of point estimates is essential to account for the spatiotemporal variability of rainfall across the river basin, which is typically achieved by applying a reduction coefficient, called the areal reduction factor (ARF). For a given basin area $A$, the ARF is the ratio of the area-average rainfall intensity over a duration $d$ with return period $T$ and the point intensity for the same $d$ and $T$. In the literature, the ARF is typically given as a function of $A$ and $d$. Comprehensive investigations were carried out by NERC (1975) that provided tabular values of ARF for a wide range of catchment areas (1 to $30000 \mathrm{~km}^{2}$ ) and rainfall durations (1 min to 25 days). Koutsoyiannis and Xanthopoulos (1999, p. 164) fitted the following empirical expression to those data:

$$
\left.\mathrm{ARF}=\max \left\{0.25,1-0.048 A^{(0.36-0.01 \ln A}\right) d^{-0.35}\right\}
$$

where $A$ is given in $\mathrm{km}^{2}$ and $d$ in hours.

However, apart from the area and duration, the shape of the basin and number of seasonal, climatic and topographic characteristics also affect the value of ARF; ARF may be also related to the return period (Veneziano and Langousis, 2005). In fact, the representation of the spatiotemporal variability of rainfall is highly uncertain, and simplistic approaches such as the ARF may result in significant errors, especially in large basins with complex topography.

\subsubsection{The runoff coefficient: just a multiplier?}

The term "runoff coefficient" is widely used in hydrology to express the percentage of rainfall that is transformed to runoff, and varies substantially with the time scale of aggregation. In the fine timescale of the rational method, it represents an overall cut-off threshold separating the effective from the total rainfall.

In general, little attention has been paid to improving guidance for selecting the runoff coefficient (Young et al., 2009). Recommended values of $C$ are usually found in lookup tables, with correspondence to soil permeability, slope and land cover, also accounting for the existence of drainage works. It is interesting that the literature mainly refers to soil classes that are common in urban or suburban areas, where $C$ may take values up to $0.70-0.90$. In the case of rural areas and pristine catchments, where $C$ is much lower, there are no well-established values for this parameter. Particularly, in the case of significantly permeable areas (e.g. karst basins), which are characterized by very low surface runoff, $C$ may be even less than 0.10 , yet such values do not appear in the literature.

Similarly to the time of concentration, and in the absence of experience, $C$ is usually treated as a constant; however, it is obvious that its value depends both on the antecedent soil moisture conditions and on the rainfall intensity. To overcome this shortcoming, it is usually suggested to employ increased values when dealing with large return periods. However, such recommendations are not based on systematic investigations, thus favouring arbitrary choices.

\subsection{The rational method in a non-deterministic framework: sources of uncertainty and a Monte Carlo experiment}

Hydrologists understood early on that designing (and managing) engineering projects based on deterministic approaches is a hopeless task and appreciated the usefulness of probabilistic approaches. In this context, they have built statistical and stochastic models to represent the multitude of uncertainties of water resource systems (involving both the natural 
and man-made processes, e.g. inflows and demands) and to quantify the related risks.

In the flood design context, the probabilistic measure of the return period of an event, $T$, is set a priori to represent the acceptable risk for all relevant quantities (peak flow, flood volume, flow depths and velocities, inundated areas, etc.). Yet, the risk related to these flooding outcomes cannot be estimated statistically, i.e. by evaluating their statistical distributions, due to common scarcity or even lack of observed data. Therefore, the return period is assigned to the input, i.e. the rainfall, for which it is easier to find records of sufficient length and accuracy. In fact, the design rainfall itself is an uncertain quantity. Typically, this is estimated from an ombrian curve, which is nothing more than a statistical model, the parameters of which are inferred from historical samples. The quantification of the uncertainty of ombrian curves is difficult, because analytical expressions for its confidence limits do not exist, except for few distributions (e.g. normal, exponential), which are however unsuitable for describing rainfall maxima. To overcome this problem, Tyralis et al. (2013) developed a Monte Carlo approach for calculating approximate confidence intervals for any distribution.

The basin's response to rainfall is also governed by inherent uncertainties, due to the complexity of flood processes, their nonlinear interactions and their dependence on the antecedent soil moisture conditions. In the rational method, which employs a very simple rainfall-runoff transformation that avoids process descriptions, these uncertainties are reflected in the model parameters, i.e. the time of concentration, the areal reduction factor and the runoff coefficient. Yet, by using the rational method with known parameters we erroneously assume that a single value of $Q_{\mathrm{p}}$ exists for a specific return period of rainfall (Viglione and Blöschl, 2009). In a deterministic context, the actual statistical behaviour of the peak discharge is represented only partially through the ombrian curve.

To demonstrate the implementation of the rational method in a non-deterministic framework, we use a hypothetical basin of $10 \mathrm{~km}^{2}$ area, for which we assume that $t_{\mathrm{c}}$ and $C$ are normally distributed, with mean $1.0 \mathrm{~h}$ and 0.40 , respectively, and standard deviation $0.25 \mathrm{~h}$ and 0.10 , respectively. Such range of uncertainty, expressed by a coefficient of variation up to 0.25 , is eminently reasonable in the estimation of the two key parameters of the rational method. The critical rainfall intensity, for given $T$ and for $d=t_{\mathrm{c}}$, is estimated by the ombrian curve provided by Koutsoyiannis and Baloutsos (2000), which is valid for the broader region of Athens. The timescale is small enough to employ an overall ARF of 0.25 , according to Eq. (2). For simplicity, we ignore rainfall uncertainty (i.e. we do not consider confidence limits for the ombrian curve), focusing only on the uncertainty of the two parameters $t_{\mathrm{c}}$ and $C$. Moreover, we (erroneously) assume that $t_{\mathrm{c}}$ and $C$ are uncorrelated, which allows using univariate distributions for generating random values of the two variables. As already discussed, $t_{\mathrm{c}}$ and $C$ are varying parameters (better modelled as random variables) that are related to rainfall and discharge; in particular, the time of concentration decreases with increasing discharge, while the runoff coefficient increases.

Based on the above assumptions, we carried out a Monte Carlo simulation, generating 1000 random values of $t_{\mathrm{c}}$ and $C$ from a truncated normal distribution, for each specific value of rainfall intensity, corresponding to return periods of 5,10 , 20, 50, 100, 200, 500 and 1000 years. For each sample of peak discharge values, we estimated its key statistical characteristics (mean, standard deviation, coefficient of skewness) as well as the empirical quantiles $5 \%$ and $95 \%$. The results are summarized in Table 1, where we also show the values derived from the deterministic application of the rational method. As expected, the deterministic design values are practically identical to the average estimations of the Monte Carlo simulation. On the other hand, for all return periods of rainfall, the peak flow values that correspond to the upper quantile are more than three times greater than the ones of the lower quantile. If we consider $Q_{95}$ for safety, the deterministic design values have to be increased by about $60 \%$.

This simple experiment illustrates clearly the significant uncertainty of the results of the rational method (more specifically, one of the sources of uncertainty) that is rarely taken into account in flood studies. Furthermore, as much more complex and data-demanding models are becoming popular, uncertainty increases significantly, thus making deterministic flood engineering nothing more than a mapping exercise.

\section{Regional formulas in flood engineering: the "recipe" for ungauged basins?}

\subsection{The concept of regionalization in hydrology}

Hydrology has a strongly empirical background, being founded on a macroscopic view of the key physical processes involved in the water cycle, in which the value of data is indisputable. Engineering hydrologists also appreciated the usefulness of data-driven approaches. These refer primarily to statistical and stochastic models that take advantage of inductive inference from measurements, in order to assess and predict the spatiotemporal evolution of the water fluxes of interest and the related probabilities (Koutsoyiannis et al., 2009).

Obviously, data-driven approaches are not directly applicable in ungauged areas. However, the estimation of fluxes in ungauged basins is made possible by accepting the notion of "hydrological similarity" and by applying the concept of regionalization. One can then build macro-scale models by analysing field data gathered in a specific basin and "transfer" the observed behaviour to "hydrologically similar" basins. The typical procedure establishes cause-effect relationships among the observed forcing data, the observed responses and some lumped, readily observable catchment 
Table 1. Summary of results with the Monte Carlo experiment using the rational method; $Q_{\text {determ }}$ is the peak flow value obtained through the deterministic application of the method.

\begin{tabular}{lrrrrrrrr}
\hline Return period, $T$ (years) & 5 & 10 & 20 & 50 & 100 & 200 & 500 & 1000 \\
Rainfall intensity, $i\left(\mathrm{~mm} \mathrm{~h}^{-1}\right)$ & 37.1 & 40.0 & 43.0 & 47.4 & 51.0 & 54.9 & 60.5 & 65.1 \\
$Q_{\text {determ }}\left(\mathrm{m}^{3} \mathrm{~s}^{-1}\right)$ & 10.3 & 11.1 & 12.0 & 13.2 & 14.2 & 15.3 & 16.8 & 18.1 \\
Average $Q\left(\mathrm{~m}^{3} \mathrm{~s}^{-1}\right)$ & 10.5 & 11.4 & 12.4 & 13.4 & 14.7 & 15.8 & 17.4 & 18.6 \\
Standard deviation $\left(\mathrm{m}^{3} \mathrm{~s}^{-1}\right)$ & 3.2 & 3.5 & 4.0 & 4.4 & 4.5 & 4.9 & 5.7 & 6.0 \\
Coefficient of skewness & 0.74 & 0.55 & 1.40 & 0.75 & 0.90 & 0.92 & 1.02 & 0.80 \\
Empirical $Q_{95}\left(\mathrm{~m}^{3} \mathrm{~s}^{-1}\right)$ & 16.4 & 17.5 & 19.0 & 20.9 & 22.3 & 24.2 & 27.0 & 29.6 \\
Empirical $Q_{5}\left(\mathrm{~m}^{3} \mathrm{~s}^{-1}\right)$ & 6.0 & 6.3 & 6.9 & 7.1 & 8.4 & 8.4 & 9.4 & 9.9 \\
\hline
\end{tabular}

properties (e.g. geomorphological), and infers the model parameters by regressing against these properties. When the basin characteristics can only be described in qualitative terms, lookup tables are used to provide feasible or recommended ranges of model parameters. Given that regional methods are established through some type of regression analysis, it follows that their performance depends also on the size and quality of the initial data sample.

However, it is also important to remark that these methods are not empirical approximations of universal hydrological laws; otherwise, there would not be so many relationships for each individual parameter, providing such different results. In addition, the concept of hydrological similarity, which is the basis of regionalization, is rather ambiguous: under which premise and which criteria and metrics are two areas considered similar? (Wagener et al., 2007). On the other hand, the "uniqueness in place" of hydrological processes, resulting from their inherent spatiotemporal variability (Beven, 2000), although correct in theory, is not in the engineering spirit that seeks practical solutions (even by means of recipes) at the macroscopic basin scale.

\subsection{Regional formulas for estimating flood model parameters: Consistent across regions?}

Regionalization methods are common in everyday flood engineering practice. They refer mainly to semi-empirical formulas or lookup tables for estimating typical parameters appearing in common modelling procedures, particularly timerelated parameters (e.g. time of concentration, time to peak, lag time), parameters related to rainfall losses (e.g. runoff coefficient, curve number) and parameters related to timearea runoff transformations (e.g. shape parameters of synthetic unit hydrographs).

Almost all widely used regionalization methods in flood hydrology were developed many decades ago, on the basis of field observations from a few experimental catchments. However, in most cases, systematic updating efforts to enrich the basis of established regional formulas with additional data or to evaluate them against local conditions are missing. Two important questions arise in this respect:
- Were the data adequate for obtaining reliable statistical conclusions?

- Can the conclusions drawn from experiments in few basins hold generally? In other words, is the diversity of natural conditions represented adequately by these basins?

In order to study the above questions, we will use as example the widely used Kirpich formula for calculating the time of concentration, $t_{\mathrm{c}}$, which is typical input for many flood models. Quoting Kirpich (1940), the experimental data were gathered "... in small agricultural areas extending in size from 1.25 to 112 acres ... all located on a farm in Tennessee ... characterized by well-defined divides and drainage channels ...typical of the steepest land under cultivation ... [where] the top soil in the steeper slopes have been washed away". Kirpich used six sets of measurements to establish a regression equation that relates $t_{\mathrm{c}}$ with the length of overland flow and the average overland slope. We surmise that Kirpich's formula would be used with more caution in practice, if this information regarding its weak basis were widely known: (a) the final data sample that was used in the regression analysis (six points) is grossly inadequate to ensure statistical consistency; and (b) the method lacks generality, due to the very small scale of the experiment (much smaller than the typical scale of application of flood studies), as well as due to the very limited diversity of geomorphologic and physiographic characteristics of the experimental areas.

It is worth mentioning that in many countries Kirpich's formula is used (at times after official recommendation) for the design of hydraulic works. This extreme example highlights the importance of being aware of the empirical, the statistical and the physical basis on which such formulas are founded. 


\subsection{Some formulas are dangerous, a few of them work somewhat and all should be adapted to local conditions: an example with the time of concentration}

In order to highlight the limitations of regional approaches in flood engineering, we employed a systematic analysis of flood data observed across Cyprus. Our objective was to assess four well-known formulas for estimating the time of concentration (Kirpich, Giandotti, SCS, Passini), which are widely used by engineers in Cyprus, through backimplementation of the rational method for estimating the peak discharge of 32 flood events. The latter were selected from an extended sample of maximum flow values at 115 hydrometric stations, according to the following criteria: (a) the upstream basin is not urbanized and is larger than $5 \mathrm{~km}^{2}$, (b) the flow is not regulated by dams, (c) the annual flow maxima series is at least 20 years long, and (d) the specific discharge exceeds $1 \mathrm{~m}^{3} \mathrm{~s}^{-1} \mathrm{~km}^{-2}$. Details on the hydrological and geographical data as well as the methodological assumptions are provided by Galiouna et al. (2011).

The ombrian curves for applying the rational method were provided by the Meteorological Service of Cyprus, which has divided Cyprus into precipitation zones with different parameters. Setting the rainfall duration equal to each of the four alternative values of $t_{\mathrm{c}}$, we estimated the critical rainfall intensity using the ombrian curve of the corresponding precipitation zone, assuming that the return period of rainfall coincides with the empirical return period of the maximum annual discharge (which is the length of the flow data, when we refer to the highest flood event). Next, we adjusted point intensities to the specific basin area and rainfall duration, by employing the reduction Eq. (2). Finally, we estimated the runoff coefficient of each basin according to the Directives for Roadwork Studies of Greece, as the sum of four components that are related to soil slope, permeability, vegetation and drainage capacity.

The estimated values of peak flows were evaluated against the observed ones using as performance criterion the coefficient of efficiency (CE), given by

$\mathrm{CE}=1-\sigma_{e}^{2} / \sigma_{y}^{2}$,

where $\sigma_{e}^{2}$ is the variance of the residuals and $\sigma_{y}^{2}$ is the variance of the observed peaks. The results for all examined approaches are summarized in Table 2. It is apparent that, apart from the Giandotti formula, which achieves a marginally satisfactory efficiency of $48 \%$, the other three empirical methods for $t_{\mathrm{c}}$ are totally inappropriate for Cyprus, as indicated by their significantly negative efficiency values. In general, these three methods significantly underestimate $t_{\mathrm{c}}$, thus providing too high discharge peaks. The noticeable superiority of the Giandotti formula proves that, in this study, the remaining assumptions (e.g. estimation of return periods, selection of runoff coefficients) play a secondary role in the overall predictive capacity of the rational method, since the
Table 2. Performance of various regional formulas for the time of concentration, $t_{\mathrm{c}}$, in terms of coefficient of efficiency $(\mathrm{CE})$ against 32 large flood events in Cyprus ( $L_{\max }$ : maximum length of main channel in $\mathrm{km} ; S$ : main channel slope; $A$ : basin area in $\mathrm{km}^{2} ; \Delta H$ : elevation difference between the centroid of the basin and its outlet in $\mathrm{m} ; \Delta H_{\mathrm{max}}$ : maximum elevation difference in $\mathrm{m} ; S_{\mathrm{b}}$ : average slope of the basin).

\begin{tabular}{lll}
\hline Method & Analytical formula for $t_{\mathrm{c}}[\mathrm{h}]$ & $\mathrm{CE}$ \\
\hline Kirpich & $0.01947\left(L_{\mathrm{max}}\right)^{0.77} S^{-0.385}$ & -3.45 \\
Giandotti & $\left(4 A^{0.5}+1.5 L\right) /\left(0.8 \Delta H^{0.5}\right)$ & 0.48 \\
SCS & $L^{1.15} /\left(7700 \Delta H_{\max }^{0.38}\right)$ & -4.02 \\
Passini & $0.108(A L)^{1 / 3} S_{\mathrm{b}}^{-0.5}$ & -4.04 \\
Calibrated Kirpich & $0.667\left(L_{\max }\right)^{0.16} S^{-0.139}$ & 0.75 \\
Calibrated Giandotti & $\left(10 A^{0.5}+0.1 L\right) /\left(0.867 \Delta H^{0.5}\right)$ & 0.73 \\
\hline
\end{tabular}

key source of uncertainty in this method (in other words, the most sensitive parameter) is the time of concentration.

In order to improve the estimations of the time of concentration, we kept the parameterization of two of the more common formulas (Giandotti and Kirpich) and optimized their numerical coefficients against the same sample of peak flows, using now CE as fitting criterion. As shown in Table 1, the performance of both methods improved considerably. In particular, the CE of the Giandotti formula increased from $48 \%$ to $73 \%$, while for the Kirpich formula there was a substantial improvement from $-345 \%$ to $75 \%$. This means that while the general structure and the explanatory variables of the two methods are conceptually consistent, the regression parameters, as given in the literature, are not. In contrast, they should be adapted to local conditions, where the key assumption of hydrological similarity may stand.

\section{Prevailing approaches for event-based flood modelling: is the recipe inherently wrong?}

\subsection{The key premise of event-based models: overland flow dominates}

In the everyday engineering practice, event-based flood models are strongly preferred over continuous ones, due to their parsimonious structure and limited data requirements. After determining the design storm, which is the sole model input, the typical computational procedure comprises two steps: (a) the estimation of rainfall losses through a conceptual model (e.g. the SCS-CN method), in order to extract the effective from the gross rainfall, and (b) the transformation of the effective rainfall to the (design) hydrograph at the basin outlet (e.g. via a unit hydrograph that represents, implicitly 
or explicitly, the propagation of water parcels across the drainage basin). For instance, the SCS-CN method requires two parameters to determine the rainfall losses, i.e. the curve number $(\mathrm{CN})$ that specifies the soil storage capacity $S$ for three classes of antecedent moisture conditions, and the initial abstraction, which is expressed as percentage of $S$. On the other hand, the unit hydrograph is synthetically determined, usually assuming a simple shape (e.g. triangular), the geometry of which is expressed using two or three parameters (e.g. base time, time to peak, peak flow).

The key assumption of this procedure is the dominance of overland flow, which is quite realistic when dealing with low-permeability basins (e.g. urban). In this vein, it is accepted that the hydrograph can be separated into two distinct components, the direct runoff and the baseflow, which represent the quick and slow response of the basin, respectively. The inflection point in the recession limb of a given flood hydrograph defines the end of direct runoff. In flood design, the baseflow component is assumed to be a small portion of the total runoff and, for convenience, also independent of the (design) rainfall. Finally, the time of concentration is used to represent the mean travel time of overland flow.

The aforementioned separation of a hydrograph in direct runoff and baseflow is grounded on Horton's overland flow theory. Horton (1931) asserted that flood runoff is generated over the entire area of a basin, when the rainfall rate exceeds the top soil's infiltration capacity; under this premise, the excess water flows quickly over the land surface to stream channels. According to Horton's perception, overland flow results only from saturation from above and deeper soil layers remain unsaturated. The remaining rainfall infiltrates to the groundwater, which in turn feeds the streamflow by means of baseflow.

\subsection{Flood flows: Hortonian or something more?}

Since the early 1960s, a number of now classical papers have disputed Horton's hypothesis, concluding that its application should be restricted to areas of low vegetation cover, where soils exhibit severe compaction or crusting, and under high rainfall intensity (Ward and Robinson, 1990, p. 223). For areas where the infiltration capacity of soils is generally high in comparison with usual rainfall intensities (e.g. forested basins), those papers proposed alternative or complementary concepts to explain the sources of flood runoff. Hewlett (1961) was the first to underline the key importance of interflow, also referred to as throughflow or subsurface stormflow (these and similar terms are used to characterize the water draining from the soil either as unsaturated flow or, more commonly, as shallow perched flow above the main groundwater level; Ward and Robinson, 1990, p. 200). Hewlett observed that, in the lower areas of a basin, the combined effects of infiltration and interflow may favour the rise of the water table up to the surface until soils become saturated. Under saturation from below conditions, all precipitation falling at whatever intensity is expected to drain as overland flow. This is in agreement with the partial-area concept (Betson, 1964), which admits that, in general, only certain parts of the basin contribute to flood runoff. In the same context, Hewlett and Hibbert (1967) contended that, during storms, ephemeral streams expand upstream by collecting overland flow and shallow subsurface flow along their channels (see also Freeze, 1972). This behaviour underpins the variable source-area concept, which is valid in areas where the water table rises to the land surface. Hewlett and Hibbert (1967) also found that the origin of floods can vary considerably in different basins. In particular, interflow is prevalent in basins with deep, permeable soils, steep straight slopes and narrow valley bottoms. Knisel (1973) commented that, although the interflow is commonly too slow to contribute appreciably to the peak of hydrographs, in terms of runoff volume it may dominate the overall response of the basin. Dunne and Black (1970) further clarified the variablesource-area theory, concluding that saturation overland flow can arise either from direct precipitation on saturated landsurface areas or from return flow of subsurface water to the surface, in saturated areas.

Summarizing these hypotheses, Beven and Kirkby (1979) classified flood runoff in at least four categories: (a) Hortonian overland flow in low-vegetated areas, (b) Betson's overland flow in variable areas of near-saturated soils, (c) Dunne and Black's direct flow in stream channels and completely saturated soils adjacent to streams, and (d) Hewlett and Hibbert's downslope lateral flow of saturated or unsaturated soil. Beven and Kirkby (1979) represented the above mechanisms in the innovative TOPMODEL, which was the first model to use topographic information to classify hydrologically similar areas.

Recent advances in data monitoring, including remote sensing and tracer technologies, enabled a better description of the rainfall-runoff processes at the small scale. In particular, significant progress on process understanding was gained from the Prediction in Ungauged Basins initiative (for a comprehensive review, see Blöschl et al., 2013 and Hrachowitz et al., 2013). New notions, such as preferential flows (Beven and Germann, 1982) and the fill-and-spill hypothesis (Tromp-van Meerveld and McDonnell, 2006), were proposed and validated via in situ experiments. These new notions challenge parts of the concepts classified by Beven and Kirkby (1979), even certain of the fundamental assumptions of the variable source-area approach (McDonnell, 2003); there is however general agreement that the Hortonian paradigm is unsuitable for representing the generation of flood flows, except for limited cases. 
Table 3. Summary information for the examined flood events at Sarantapotamos and Peristerona basins.

\begin{tabular}{lllll}
\hline River basin & Sarantapotamos & Sarantapotamos & Peristerona & Peristerona \\
\hline Flood event & $27 / 2-2 / 3 / 2012$ & $21 / 2-25 / 2 / 2013$ & $8 / 3-15 / 3 / 1988$ & $11 / 1-14 / 1 / 2004$ \\
Total rainfall $(\mathrm{mm})$ & 37.3 & 41.2 & 102.3 & 149.0 \\
Total runoff $(\mathrm{mm})$ & 2.9 & 7.1 & 60.8 & 51.3 \\
Runoff coefficient $(\%)$ & 7.8 & 17.2 & 59.3 & 34.3 \\
Obs. peak flow $\left(\mathrm{m}^{3} \mathrm{~s}^{-1}\right)$ & 5.9 & 32.9 & 21.3 & 52.1 \\
Sim. peak flow $\left(\mathrm{m}^{3} \mathrm{~s}^{-1}\right)$ & 8.0 & 49.0 & 84.2 & 99.0 \\
\hline
\end{tabular}

\subsection{Can flood models work in semi-arid areas without soil moisture balance? Lessons learned from two small Mediterranean catchments}

The improved understanding of the flood generation mechanisms resulted in increasingly complex model structures, with increased requirements on data and computational resources. In particular, high data requirements make proper application of complex models exceedingly difficult outside the research environment. For this reason, the engineering community prefers using much simpler tools, particularly event-based models that are straightforward to implement, when their (few) parameters are directly obtained from bibliographic sources (i.e. regional formulas or lookup tables). Yet, these engineering recipes, and specifically the unit hydrograph approach, are founded on Horton's interpretation of flood generation that ignores the flow through the shallow soil, generally referred to as interflow. Most of the synthetic unit hydrographs that are applied in ungauged basins relate their parameters (e.g. base time, time to peak, peak flow) to the surface properties of the catchment (e.g. slope, area, geometry of drainage network). The hidden yet obvious hypothesis under this premise is that the entire effective rainfall flows over the basin surface.

As mentioned in Sect. 4.1, the typical model for extracting the effective rainfall from the design hyetograph is the SCS-CN method. In fact, this is a Hortonian-based approach that ignores soil moisture accounting, as far as the sum of infiltrated water is considered as losses, which in turn results in severe underestimation of the volume and duration of design hydrographs. Several researchers have revealed the limitations of the SCS-CN method with respect to soil processes and proposed further parameterization to better represent the initial soil moisture conditions (e.g. Ponce and Hawkins, 1996; Michel et al., 2005; Sahu et al., 2007) as well as the infiltration (e.g. Gabellani et al., 2008; Grimaldi et al., 2013) and baseflow (e.g. Coustau et al., 2012) processes. Implementations of the SCS-CN method in a continuous simulation mode within hybrid modelling schemes have been also developed in order to represent the variability of rainfall and the antecedent soil moisture conditions (e.g. Camici et al., 2011; Grimaldi et al., 2012a, b). Despite these improvements, the major inconsistency of the method, i.e. the overland flow hypothesis, remains, and is further amplified when SCS-CN is combined with a unit hydrograph to route the effective rainfall across the basin.

We demonstrate the shortcomings of the combined SCS$\mathrm{CN}$ and synthetic unit hydrograph (henceforth SCS/SUH) procedure with examples from two typical Mediterranean catchments, in Eastern Greece (Sarantapotamos, $144.6 \mathrm{~km}^{2}$ ) and Cyprus (Peristerona, $77.0 \mathrm{~km}^{2}$ ). Semi-arid climatic conditions prevail in both areas, yet these basins exhibit substantially different hydrological behaviour. This is due to the different geological characteristics of these two basins. Specifically, Sarantapotamos Basin is underlain entirely by limestone and dolomite, which strongly favour deep percolation instead of runoff. For this reason, its flow regime is ephemeral, with mean annual runoff coefficient of about $5 \%$. Since 2011, the basin is part of a research network comprising four pilot basins in Greece (Efstratiadis et al., 2013). Peristerona Basin is located in the Troodos Mountains, central Cyprus, and is mainly underlain by diabase and basalt that are part of the Troodos ophiolite. Although the flow regime is intermittent (the stream is drying during summer months but maintains a usually small baseflow during the wet period), floods with significant peak flows occur there, which are the highest in all of Cyprus. The basin has been systematically monitored since the 1960s.

Michailidi et al. (2013) investigated several modelling schemes for the two basins, by analysing all important flood events during the corresponding periods of observation. In the context of the SCS/SUH approach, they developed a parametric synthetic unit hydrograph comprising a linear rising branch and a nonlinear falling one. In order to preserve the major assumption of the SCS-CN method, i.e. the dominance of the overland flow, they set its base time equal to the time of concentration of the basin $t_{\mathrm{c}}$, expressing the time to peak as fraction of $t_{\mathrm{c}}$. The latter was estimated by the Giandotti formula ( $6.5 \mathrm{~h}$ for Sarantapotamos and $3.5 \mathrm{~h}$ for Peristerona). In order to eliminate the impacts of initial soil moisture conditions, the three, in total, parameters of the combined SCS/SUH method (i.e. the curve number, the initial abstraction ratio and the dimensionless time to peak) were calibrated against each specific flood event. The objective function included an efficiency term, to ensure the closest fit to the corresponding observed hydrograph, and two penalty terms, one 

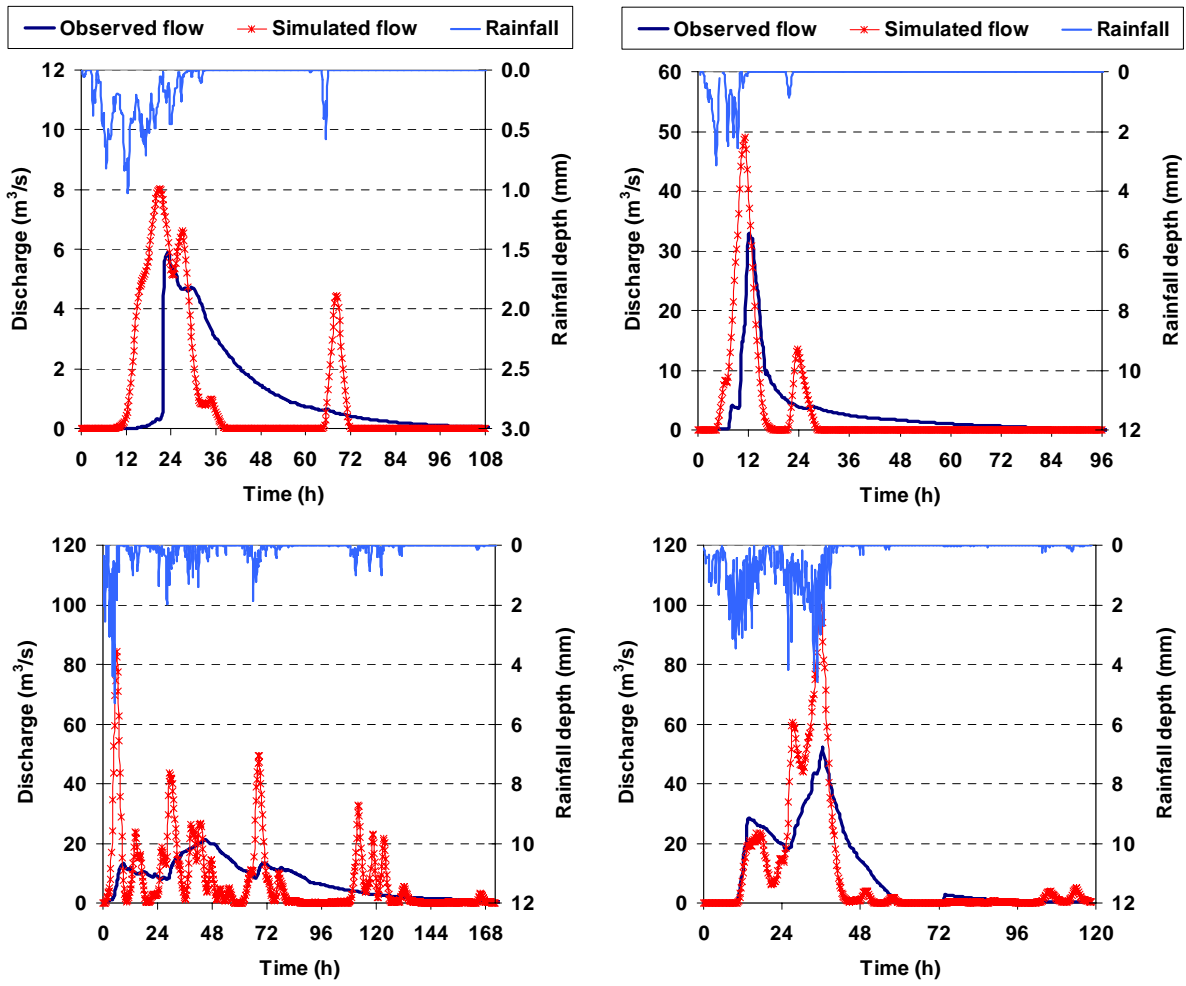

Figure 1. Observed and simulated (through the SCS/SUH method) hydrographs and corresponding rainfall events in Sarantapotamos (upper panel; February 2012, left, and February 2013, right) and Peristerona (lower panel; March 1988, left, and January 2004, right).

for the conserving the flood volume and one for approximating the peak discharge.

In most events the standard SCS/SUH method failed to predict the flood flows adequately; this finding agrees with the results of similar studies in semi-arid Mediterranean catchments (Soulis et al., 2009; Massari et al., 2014). Characteristic failure cases (two from each basin), which refer to the largest observed storm events, are shown in Fig. 1 (see also summary data in Table 3). All observed hydrographs show that: (a) the basin's response to rainfall is quite slow; (b) generally smooth shapes are produced, even for storm events of complex structure; and (c) after the end of rainfall, flood runoff continues much longer than the corresponding time of concentration, which determines the travel time of overland flow. The common interpretation of the above characteristics is the existence of a significant regulation mechanism, which is the shallow soil (unsaturated zone). As result of the semiarid climate, at the beginning of rainfall the soil is mostly far from saturation and allows storing all infiltrating water without generating runoff. After exceeding a certain threshold, there is a sharp increase of flood runoff until the peak value, followed by a recession (i.e. the falling limb of the hydrographs) that can be represented well as outflow from a linear reservoir. This behaviour indicates that the excess water begins moving through the soil as interflow, which seems to be the dominant (if not the sole) component of all observed hydrographs.

Due to the limitations of the modelling scheme, none of above important characteristics is represented in the simulated hydrographs. In particular, the standard SCS/SUH procedure cannot handle complex rainfall patterns, nor can it produce interflow, which is a rather smooth and slow flux (in contrast to overland flow, which generally follows the pattern of rainfall), because SCS/SUH does not strictly include a soil moisture balance. Moreover, since most of runoff flows through the soil, the response time of the basin should be much longer than the time of concentration. However, by implementing the erroneous assumption of overland flow, thus setting the duration of the SUH equal to $t_{\mathrm{c}}$, we forced the model to calculate too narrow hydrographs. This explains the substantially poor reproduction of the falling limbs and the significant overestimation of the observed peak flows, due to the conservation of the volumes. These observations suggest that a radically different conceptualization is needed, in which interflow is proportional to soil moisture storage; furthermore, the base time of the SUH has to be substantially increased, to account for the actual travel time of flood runoff through the shallow soil. 


\section{Conclusions}

Flood design and modelling is more than blind application of "recipes", regardless of the sophistication of the underlying predictive tools. Caution is recommended, because few of the methodologies and modelling tools available in the literature, of any level of complexity, have been tested extensively against flood data observed in many different catchments worldwide. In this vein, hydrological experience (and, why not, intuition) is of key importance to prevent misuse of these tools as well as to properly account for underlying uncertainties, which are apparent in all aspects of flood modelling.

Particularly regarding predictions in ungauged basins, (a) the user must know a model's validation basis, statistical and physical, and (b) predictions with modelling tools that use regionalized parameters cannot be trusted before validation at some local setting. This is of key importance in the case of small and semi-arid Mediterranean basins, which exhibit many peculiarities in their hydrological behaviour.

Specifically regarding the rational method, (a) the time of concentration as "basin constant" has been identified as enigmatic, because although $t_{\mathrm{c}}$ is assumed to be an independent variable that explicitly determines $Q_{\mathrm{p}}$, it is actually dependent on $Q_{\mathrm{p}}$; (b) estimating $t_{\mathrm{c}}$ with four established empirical formulas yielded disparate and also unrealistic results, which, however, improved considerably after optimizing the numerical coefficients of two of these formulas against the same locally observed peak flows in Cyprus; and (c) the rational method's deterministic application can give significantly lower peak flows compared to upper-quantile results of related Monte Carlo simulations.

The different aspects of uncertainty in flood modelling are only partially represented by the return period of the design rainfall. A more consistent approach would require integrating the uncertainties of all associated components, including model input, model parameters and initial conditions. Such an option can be offered by stochastic simulation, which is the most effective and powerful technique for analysing systems of high complexity and uncertainty. In particular, the model parameters (many of which are, in fact, variable) reflect the high complexity of the flood system. In the context of stochastic simulation, these should be treated as random variables, to which are assigned proper statistical distributions.

The benefits of stochastic simulation also include the generation of synthetic storm data. In most routine flood studies employing event-based models, the shape of the design hyetograph is very simple. Typically, a single-pulse storm event is considered with a single rainfall peak, which generates infiltration patterns that lead to a single flood peak. However, if a Monte Carlo approach is adopted, using ensembles of synthetic storm events provided by stochastic models, the latter will have arbitrary temporal distributions, comprising both single and multiple pulses within the same storm event.
By analysing several flood events in two catchments in Greece and Cyprus, we have illustrated the intrinsic shortcomings of the SCS/SUH procedure, when applied in semiarid areas. This empirical analysis also confirmed that the implementation of a soil moisture accounting scheme is essential for a proper modelling of flood generation. This can be achieved via one or more interconnected conceptual tanks. Yet, conceptual models are not easily applied to ungauged basins, since their parameters cannot be derived through regional approaches but must be estimated via calibration. Nevertheless, engineering hydrology can take advantage of the available data from a plethora of experimental basins worldwide, to establish appropriate formulas for these parameters. In our opinion, more attention should be paid to conceptual flood modelling, which can ensure both physical consistency and parsimony. This also involves the formulation of synthetic unit hydrographs that ensure a realistic representation of the time-area transformations, which are employed not only over the basin surface but also through the unsaturated zone.

Acknowledgements. The research for this paper was performed within the project "DEUCALION - Assessment of flood flows in Greece under conditions of hydroclimatic variability: Development of physically-established conceptual-probabilistic framework and computational tools", funded by the General Secretariat of Research \& Technology of Greece (http://deucalionproject.gr/). It is based on ideas presented at the mid-term conference of COST Action ES0901, titled "Advanced methods for flood estimation in a variable and changing environment". We wish to thank Thomas Kjelsen and Athanasios Loukas for their kind invitation. We are also grateful to Luca Brocca, Salvatore Grimaldi and an anonymous reviewer for their comments during the discussion phase, which contributed to an improved presentation of the paper.

Edited by: A. Loukas

Reviewed by: S. Grimaldi and one anonymous referee

\section{References}

Betson, R. P.: What is watershed runoff? J. Geoph. Res., 69, 15411552, 1964.

Beven, K. J.: Uniqueness of place and process representations in hydrological modelling, Hydrol. Earth Syst. Sci., 4, 203-213, doi:10.5194/hess-4-203-2000, 2000.

Beven, K. J. and Germann, P.: Macropores and water flow in soils, Water Resour. Res., 18, 1311-1325, doi:10.1029/WR018i005p01311, 1982.

Beven, K. J. and Kirkby, M. J.: A physically based, variable contributing area model of basin hydrology, Hydrol. Sci. Bul., 24, 43-69, 1979.

Blöschl, G., Sivapalan, M., Wagener, T., Viglione, A., and Savenije, H. H. G.: Runoff Prediction in Ungauged Basins: Synthesis across Processes, Places and Scales, Cambridge University Press, 2013. 
Camici, S., Tarpanelli, A., Brocca, L., Melone, F., and Moramarco, T.: Design soil moisture estimation by comparing continuous and storm-based rainfall-runoff modelling, Wat. Resour. Res., 47, W05527, doi:10.1029/2010WR009298, 2011.

Chow, V. T.: Handbook of Applied Hydrology, McGraw-Hill Book Company, 1964.

Coustau, M., Bouvier, C., Borrell-Estupina, V., and Jourde, H.: Flood modelling with a distributed event-based parsimonious rainfall-runoff model: case of the karstic Lez river catchment, Nat. Hazards Earth Syst. Sci., 12, 1119-1133, doi:10.5194/nhess-12-1119-2012, 2012.

Dunne, T. and Black, R. D.: Partial area contributions to storm runoff in a small New England watershed, Water Resour. Res., 6, 1296-131, 1970.

Efstratiadis, A., Koussis, A. D., Lykoudis, S., Koukouvinos, A., Christofides, A., Karavokiros, G., Kappos, N., Mamassis, N., and Koutsoyiannis, D.: Hydrometeorological network for flood monitoring and modeling, Proc. SPIE 8795, First International Conference on Remote Sensing and Geoinformation of the Environment (RSCy2013), 879510, 2013.

Freeze, R. A.: The role of subsurface flow in the generation of surface runoff, 2. Upstream source areas, Water Resour. Res., 8, 1272, doi:10.1029/WR008i005p01272, 1972.

Gabellani, S., Silvestro, F., Rudari, R., and Boni, G.: General calibration methodology for a combined Horton-SCS infiltration scheme in flash flood modeling, Nat. Hazards Earth Syst. Sci., 8, 1317-1327, doi:10.5194/nhess-8-1317-2008, 2008.

Galiouna, E., Efstratiadis, A., Mamassis, N., and Aristeidou, K.: Investigation of extreme flows in Cyprus: empirical formulas and regionalization approaches for peak flow estimation, EGU General Assembly 2011, Geophys. Res. Abstr., 13, 2077, http: //itia.ntua.gr/1117/, Vienna, 2011.

Grimaldi, S., Petroselli, A., and Serinaldi, F.: A continuous simulation model for design-hydrograph estimation in small and ungauged watersheds, Hydrol. Sci. J., 57, 1035-1051, doi:10.1080/02626667.2012.702214, 2012a.

Grimaldi, S., Petroselli, A., and Serinaldi, F.: Design hydrograph estimation in small and ungauged watersheds: continuous simulation method versus event-based approach, Hydrol. Process., 26, 3124-3134, doi:10.1002/hyp.8384, 2012b.

Grimaldi, S., Petroseli, A., Tauro, F., and Porfiri, M.: Time of concentration: A paradox in modern hydrology, Hydrol. Sci. J., 57, 217-228, 2012c.

Grimaldi, S., Petroseli, A., and Romano, N.: Curve-Number/GreenAmpt mixed procedure for streamflow predictions in ungauged basins: Parameter sensitivity analysis, Hydrol. Process., 27, 1265-1275, 2013.

Hewlett, J. D.: Watershed management, Report for 1961 Southeastern Forest Experiment Station, US Forest Service, Ashville, N.C., 1961.

Hewlett, J. D. and Hibbert, A. R.: Factors affecting the response of small watersheds to precipitation in humid areas, Forest Hydrology, edited by: Sopper, W. E. and Lull, H. L., Pergamon, Oxford, 275-290, 1967.

Horton, R. E.: The field, scope, and status of the science of hydrology, Trans. AGU, Reports and Papers, Hydrology, National Research Council, Washington, DC, 1931.

Hrachowitz, M., Savenije, H. H. G., Blöschl, G., McDonnell, J. J., Sivapalan, M., Pomeroy, J. W., Arheimer, B., Blume, T., Clark,
M. P., Ehret, U., Fenicia, F., Freer, J. E., Gelfan, A., Gupta, H. V., Hughes, D. A., Hut, R. W., Montanari, A., Pande, S., Tetzlaff, D., Troch, P. A., Uhlenbrook, S., Wagener, T., Winsemius, H. C., Woods, R. A., Zehe, E., and Cudennec, C.: A decade of Predictions in Ungauged Basins (PUB) - a review, Hydrol. Sci. J., 58, 1198-1255, 2013.

Huber, W. C.: Discussion of "Estimating urban time of concentration” by R. H. McCuen et al., J. Hydraul. Eng., 113, 122-124, 1987.

Kirpich, Z. P.: Time of concentration of small agricultural watersheds, Civil Eng., 10, 362, 1940.

Knisel, W. G.: Comments on "Role of subsurface flow in generating surface runoff” by R. A. Freeze, Water Resour. Res., 9, 1107, doi:10.1029/WR009i004p01107, 1973.

Koussis, A. D.: An assessment review of the hydraulics of storage flood routing 70 years after the presentation of the Muskingum method, Hydrol. Sci. J., 54, 43-61, 2009.

Koussis, A. D.: Reply to the Discussion of "Assessment and review of the hydraulics of storage flood routing 70 years after the presentation of the Muskingum method" by M. Perumal, Hydrol. Sci. J., 55, 1431-1441, 2010.

Koutsoyiannis, D.: Statistics of extremes and estimation of extreme rainfall: 1. Theoretical investigation, Hydrol. Sci. J., 49, 575590, 2004a.

Koutsoyiannis, D.: Statistics of extremes and estimation of extreme rainfall: 2. Empirical investigation of long rainfall records, Hydrol. Sci. J., 49, 591-610, 2004 b.

Koutsoyiannis, D.: Reconciling hydrology with engineering, Hydrol. Res., 45, 2-22, doi:10.2166/nh.2013.092, 2014.

Koutsoyiannis, D. and Baloutsos, G.: Analysis of a long record of annual maximum rainfall in Athens, Greece, and design rainfall inferences, Nat. Hazards, 22, 29-48, 2000.

Koutsoyiannis, D. and Xanthopoulos, Th.: Engineering Hydrology, Edition 3, 418 pp., National Technical University of Athens, Athens, 1999 (in Greek).

Koutsoyiannis, D., Makropoulos, C., Langousis, A., Baki, S., Efstratiadis, A., Christofides, A., Karavokiros, G., and Mamassis, N.: HESS Opinions: "Climate, hydrology, energy, water: recognizing uncertainty and seeking sustainability", Hydrol. Earth Syst. Sci., 13, 247-257, doi:10.5194/hess-13-247-2009, 2009.

Kuichling, E.: The relation between the rainfall and the discharge of sewers in populous districts. Trans. Amer. Soc. Civ. Eng., 20, 1-56, 1889.

Kundzewicz, Z. W., Pińskwar, I., and Brakenridge, G. R.: Large floods in Europe, 1985-2009, Hydrol. Sci. J., 58, 1-7, 2013.

Massari, C., Brocca, L., Barbetta, S., Papathanasiou, C., Mimikou, M., and Moramarco, T.: Using globally available soil moisture indicators for flood modelling in Mediterranean catchments, Hydrol. Earth Syst. Sci., 18, 839-853, doi:10.5194/hess-18-8392014, 2014.

McCuen, R. H.: Uncertainty analyses of watershed time parameters, J. Hydrol. Eng., 14, 490-498, 2009.

McDonnell, J. J.: Where does water go when it rains? Moving beyond the variable source area concept of rainfall-runoff response, Hydrol. Process., 17, 1869-1875, 2003.

Michaelidi, E., Mastrotheodoros, T., Efstratiadis, A., Koukouvinos, A., and Koutsoyiannis, D.: Flood modelling in river basins with highly variable runoff, 5th EGU Leonardo Conference - Hy- 
drofractals 2013 - STAHY '13, Kos Island, Greece, available at: http://itia.ntua.gr/1385/, 2013.

Michel, C., Andréassian, V., and Perrin, C.: Soil Conservation Service Curve Number method: How to mend a wrong soil moisture accounting procedure?, Water Resour. Res., 41, W02011, doi:10.1029/2004WR003191, 2005.

Mulvaney, T. J.: On the use of self-registering rain and flood gauges in making observations of the relations of rainfall and flood discharges in a given catchment, Proc. Inst. Civil Eng. Ireland, 4, 19-31, 1851.

National Environmental Research Council (NERC): Flood Studies Report, Institute of Hydrology, Wallingford, 1975.

Papalexiou, S. M. and Koutsoyiannis, D.: Entropy based derivation of probability distributions: A case study to daily rainfall, Adv. Water Resour., 45, 51-57, 2012.

Ponce, V. M. and Hawkins, R. H.: Runoff curve number: Has it reached maturity?, J. Hydrol. Eng., 1, 11-18, 1996.

Sahu, R. K., Mishra, S. K., Eldho, T. I., and Jain, M. K.: An advanced soil moisture accounting procedure for SCS curve number method, Hydrol. Process., 21, 2872-2881, 2007.

Soulis, K. X., Valiantzas, J. D., Dercas, N., and Londra, P. A.: Investigation of the direct runoff generation mechanism for the analysis of the SCS-CN method applicability to a partial area experimental watershed, Hydrol. Earth Syst. Sci., 13, 605-615, doi:10.5194/hess-13-605-2009, 2009.
Tromp-van Meerveld, H. J., and McDonnell, J. J.: Threshold relations in subsurface stormflow: 2. The fill and spill hypothesis, Water Resour. Res., 42, W02411, doi:10.1029/2004WR003800, 2006.

Tyralis, H., Koutsoyiannis, D., and Kozanis, S.: An algorithm to construct Monte Carlo confidence intervals for an arbitrary function of probability distribution parameters, Comput. Stat., 28, 1501-1527, 2013.

Veneziano, D. and Langousis, A.: The areal reduction factor: A multifractal analysis, Water Resour. Res., 41, W07008, doi:10.1029/2004WR003765, 2005.

Viglione, A. and Blöschl, G.: On the role of storm duration in the mapping of rainfall to flood return periods, Hydrol. Earth Syst. Sci., 13, 205-216, doi:10.5194/hess-13-205-2009, 2009.

Wagener, T., Sivapalan, M., Troch, P., and Woods, R.: Catchment classification and hydrologic similarity, Geography Compass., 1, 901-931, 2007.

Ward, R. C. and Robinson, M.: Principles of Hydrology, 3rd Edn., McGraw-Hill, London, 1990.

Young, C. B., McEnroe, B. M., and Rome, A. C.: Empirical determination of rational method runoff coefficients, J. Hydrol. Eng., 14, 1283-1289, 2009. 